\title{
Model-Based Development of a Meta-Learning Support System: Taking a Presentation-Based Meta-Learning Scheme as an Example
}

\author{
Kazuhisa Seta*, Hiroshi Maeno* and Mitsuru Ikeda**
}

(Received 11 June 2011 and accepted in revised form 5 January 2012)

\begin{abstract}
It is difficult to generalize experiences of system development as methodologies for building meta-learning support systems. Thus, the importance of a model-based system development approach has been recognized. Such an approach contributes to systematic refinement of learning systems according to the model and moreover, knowledge can be accumulated on meta-learning system development based on it. In this paper, we adopt a model-oriented approach and undertake the following: (i) we adopt Kayashima's computational model as a basis to build a meta-learning process model and we extend it for meta-learning activities; (ii) we conceptualize five concepts that clarify the means to remove or eliminate the factors of difficulty; then (iii) we clarify design rationales of support functions embedded into our system to facilitate meta-learning processes based on the meta-learning process model.
\end{abstract}

Keywords: model-based system development, meta-learning support system, meta-learning, presentation-based learning

\section{Introduction}

The importance of a model-based system development approach has been recognized by many researchers $^{(1-3)}$. Such an approach contributes to systematic refinement of learning systems by iterating a loop that builds a model to clarify the learning system design rationale, developing and evaluating the learning system according to the model, and revising the model based on the learning system. Moreover, the model can accumulate knowledge related to meta-learning system development.

We adopt a model-oriented approach by referring to Kayashima's model ${ }^{(4,5)}$ which is a sophisticated and useful framework to clarify factors of difficulty in performing meta-cognitive activities for problem-solving and add two factors of difficulty in performing metacognitive activities for learning processes. Then, we specify design concepts for a meta-learning scheme as a means to remove or eliminate the factors of difficulty. Moreover, we clarify design rationales of support functions embedded into our presentation-based meta-learning support system based on our previously derived

\footnotetext{
* Osaka Prefecture University, Japan

** Japan Advanced Institute of Science and Technology, Japan
}

meta-learning process model ${ }^{(6)}$. Experimental issues and details of concrete functions embedded into the system were explained in that earlier reference.

\section{Meta-Learning Process Model}

Our research is designed to produce a meta-learning support system that facilitates learners' learning skill development through reflecting onto their own learning processes. We designate "learning of learning activities" as meta-learning in making presentation materials.

On the other hand, performing meta-cognitive activities in performing learning processes (planning and controlling of learning processes) is usually more difficult than problem-solving, because a problem, problemsolving activities, and their results are usually visible in a course study: (1) if problems are given to users as a problem-solving task in the outside world, they can recognize them more easily, and (2) problem-solving processes are often required to be described (thus they become visible), whereas those of learning activities and their results (learner's understanding states) are invisible in each person's own mind.

We provide a detailed model of meta-learning activities in Figure 1, which depicts a meta-learning process model by extending Kayashima's computational model. As we describe in the following, we newly add 


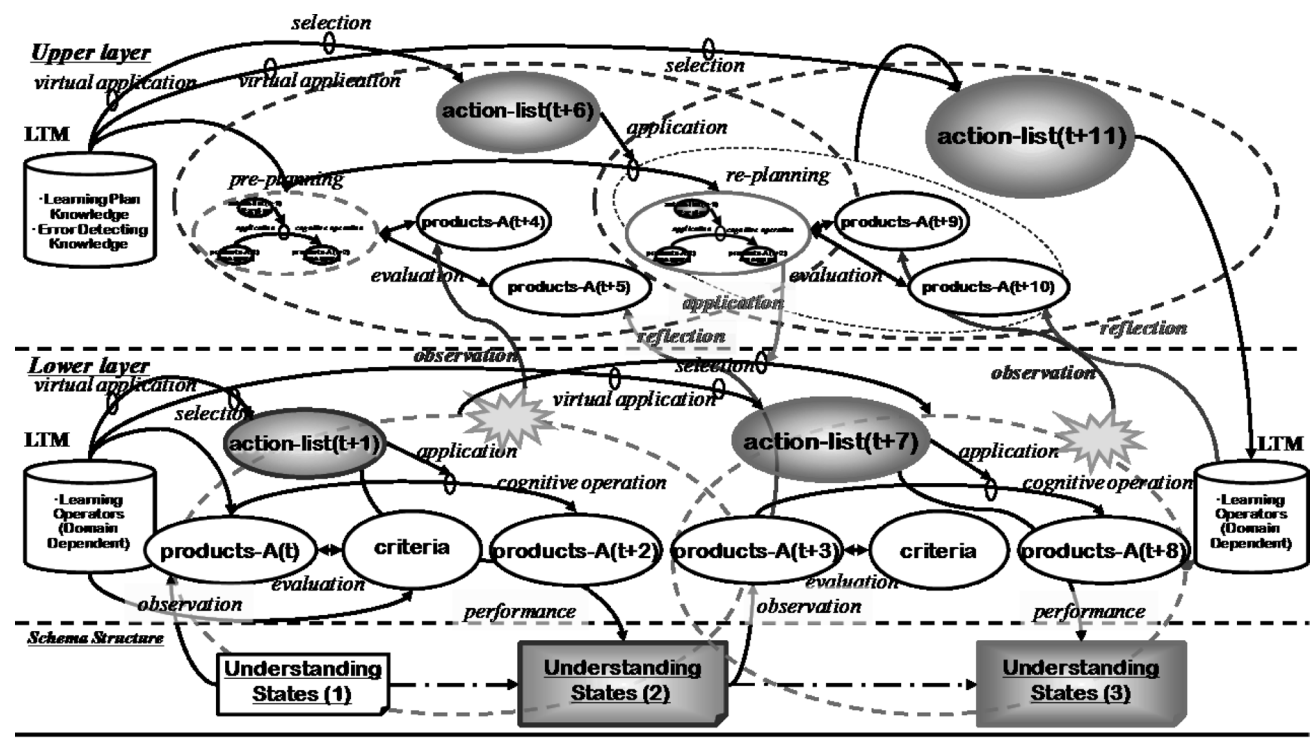

Outside World

Figure 1. Meta-Learning Process Model.

(i) a schema layer to the original model; and we model (ii) acquiring the activity of learning methods and (iii) modifying activity of criteria to evaluate each individual's own state of understanding.

The model has three layers. At the lowest layer in the figure, i.e., the schema level, "real status" of a learner's understanding state is represented by performing learning activities. The upper two layers capture metalearning processes in a learner's mind (working memory, WM). Changing processes of the learner's understanding state by monitoring the learner's own schema are situated in the lower layer of the WM. Separate representation of the schema level and the lower layer of the WM makes it possible to represent differences between the "leaner's real state of his/her understanding" and the "learner's belief about his/her own understanding states." The learner's belief about her own understanding states is not always produced or modeled by monitoring their real states. It is important to characterize meta-cognition in learning because meta-cognitive activity is prompted by the awareness on the gap between the real state and the belief.

Planning of learning processes is represented in the upper layer of the WM. Processes of reflecting activities for acquiring learning skills (acquiring domain-specific learning operators, and modifying criteria to evaluate individual understanding states) are represented in the upper layer. Each ellipse shows the product made at each layer, and " $t *$ " represents time: the " $t *$ " order represents product changes.

We examine Kayashima's model ${ }^{(4,5)}$ for detailed meanings of operators such as application, selection, and evaluation, which appear in the model. Although, the model is depicted in a domain-independent manner, we take the approach of learning abstract factory (AF) design patterns to make understanding easier. A learner planned to understand the features of functional extendibility of the AF pattern in the software design pattern (action-list $(\mathrm{t}+1))$ in the lower layer of the WM. Thereafter, she carried out learning activities that caused changes of her understanding state (Understanding States (2)) and she thought she could understand the extensibility of AF (products-A $(\mathrm{t}+2)$ ), but actually she could not understand it. She then realized her own lack of understanding (products- $\mathrm{A}(\mathrm{t}+3)$ ) (gap of real states at the schema level and her belief) by performing on-going monitoring or reflective-monitoring (explained in Section 4) and created one product, (products-A $(\mathrm{t}+4)$ ) by on-going monitoring or (products- $\mathrm{A}(\mathrm{t}+5))$ by reflective-monitoring, respectively, and decided to re-plan her 
Table 1. Factors of Difficulty of Performing Meta-Learning Processes.

\begin{tabular}{|c|c|c|c|c|c|c|}
\hline Target & Cognitive activity & Rehearsal & Observation & Evaluation & $\begin{array}{c}\text { Virtual } \\
\text { application }\end{array}$ & Selection \\
\hline Schema & Understanding state at own schema (a) & & (d2) & & & \\
\hline \multirow{2}{*}{$\begin{array}{c}\text { Outside } \\
\text { world }\end{array}$} & Resulting object of others' learning processes (b) & & $(\mathrm{d} 2)(\mathrm{d} 3)$ & & & \\
\hline & Others' learning processes (c) & & $(\mathrm{d} 1)(\mathrm{d} 2)(\mathrm{d} 3)(\mathrm{d} 4)$ & & & \\
\hline LTM & Object in LTM (d) & (d5) & (d5) & & & \\
\hline \multirow{7}{*}{$\begin{array}{c}\text { Products } \\
\text { in WM }\end{array}$} & $\begin{array}{l}\text { Observing product of one's own understanding state at the } \\
\text { schema (e) }\end{array}$ & (d5) & & (d5) & (d5) & (d5) \\
\hline & $\begin{array}{l}\text { Observing product of resulting object of others' learning } \\
\text { processes (f) }\end{array}$ & (d5) & & (d5) & (d5) & (d5) \\
\hline & Observing product of others' cognitive operation process (g) & $(\mathrm{d} 5)(\mathrm{d} 6)$ & & $(\mathrm{d} 5)(\mathrm{d} 6)$ & $(\mathrm{d} 5)(\mathrm{d} 6)$ & $(\mathrm{d} 5)(\mathrm{d} 6)$ \\
\hline & Resulting object of one's own learning processes (h) & (d5) & $(\mathrm{d} 2)(\mathrm{d} 4)(\mathrm{d} 5)(\mathrm{d} 7)$ & & & \\
\hline & One's own learning processes (i) & $(\mathrm{d} 5)(\mathrm{d} 6)$ & $\begin{array}{c}(\mathrm{d} 1)(\mathrm{d} 2)(\mathrm{d} 3) \\
(\mathrm{d} 5)(\mathrm{d} 6)(\mathrm{d} 7)(\mathrm{d} 8)\end{array}$ & & & \\
\hline & $\begin{array}{l}\text { Observing product of resulting object (understanding state) of } \\
\text { one's own learning processees (j) }\end{array}$ & $(\mathrm{d} 5)(\mathrm{d} 6)$ & & $(\mathrm{d} 5)(\mathrm{d} 6)$ & & $(\mathrm{d} 5)(\mathrm{d} 6)$ \\
\hline & Observing product of one's own learning processes (k) & $(\mathrm{d} 5)(\mathrm{d} 6)$ & & $\begin{array}{c}(\mathrm{d} 3)(\mathrm{d} 5)(\mathrm{d} 6)(\mathrm{d} 8) \\
(\mathrm{d} 9)(\mathrm{d} 10)(\mathrm{d} 11)\end{array}$ & $\begin{array}{l}(\mathrm{d} 3)(\mathrm{d} 5)(\mathrm{d} 6) \\
(\mathrm{d} 8)(\mathrm{d} 9)\end{array}$ & $\begin{array}{l}(\mathrm{d} 3)(\mathrm{d} 5) \\
(\mathrm{d} 6)(\mathrm{d} 8)\end{array}$ \\
\hline \multicolumn{2}{|c|}{$\begin{array}{l}\text { (d1) Segmentation of process } \\
\text { (d2) Invisibility } \\
\text { (d3) Simultaneous processing with other activities } \\
\text { (d4) Inference of cognitive operation }\end{array}$} & $\begin{array}{l}\text { ocessing w } \\
\text { resource } \\
\text { ing }\end{array}$ & rehearsal (d & $\begin{array}{l}\text { Acquisition of lear } \\
\text { Acquisition of crit }\end{array}$ & $\begin{array}{l}\text { rning operator } \\
\text { teria for learnin }\end{array}$ & g processes \\
\hline
\end{tabular}

learning processes by adopting different learning operators (action-list $(\mathrm{t}+6))$ in the upper layer. Eventually, she chose other learning operators (e.g. "Understand extendibility of AF by considering functional class structures") and generated a new learning plan in the lower layer (action-list $(\mathrm{t}+7))$.

She will be able to understand the topic more deeply (Understanding States (3)), if these meta-cognitive activities (learning process planning) are adequately performed.

Learning-skill acquisition processes in the upper layer (action-list $(t+11))$ require the following cognitive activities: (i) reflecting upon and observing the learning processes in the lower level, (ii) detecting meaningful domain-specific learning operators that deepened understanding states; (iii) re-evaluating, generalizing, and storing them in long-term memory; and (iv) modifying criteria based on them.

\section{Factors of Difficulty in Performing Meta-Learning Activities}

Table 1 represents factors of difficulty in performing meta-cognitive activities for learning processes.
Based on the framework of Kayashima et al. ${ }^{(4,5)}$, we add two primitives to represent factors of difficulty for metalearning. i.e., acquisition of the learning operator and acquisition of the learning criteria. It is notable that the subjects of observation are an individual's own invisible understanding states and learning processes in performing meta-learning $((\mathrm{e})-(\mathrm{g}))$.

By observing objects in the scheme, a corresponding representation is created in the WM: "Observing the product of one's understanding state." Because one's own objects in the scheme are invisible (d2), observing the product of one's understanding state becomes incomplete.

Activities from (e)-(g) are performed in the lower layer of the WM, while those from (h)-(k) are performed in the upper layer of the WM. We briefly explain factors of difficulty especially in performing meta-cognitive activities in learning $((\mathrm{h})-(\mathrm{k}))$.

Regarding (h) and (i), they represent factors of difficulty in performing reflective monitoring and on-going monitoring (explained in Section 4), respectively. In performing reflective monitoring (h), that observes the resulting object of one's own learning processes, the difficulties of (d2) invisibility, (d4) inference of cognitive 
Table 2. Correspondence among Concrete Function Based on Support Concepts and Their Targets.

\begin{tabular}{|c|c|c|c|}
\hline Conceptualization & Meaning & Target to eliminate factors of difficulties & Learning Scheme Design \\
\hline SHIFT & $\begin{array}{l}\text { Stagger the time of developing learning } \\
\text { skills after performing problem-solving } \\
\text { processes }\end{array}$ & $\begin{array}{l}\text { - (d5) Simultaneous processing with other activities } \\
\text { - (d6) Management of resource } \\
+ \text { (d4) Inference of cognitive operation }\end{array}$ & $\begin{array}{l}\text { Task Design (giving a } \\
\text { presentation topic the } \\
\text { learner had already } \\
\text { learned) }\end{array}$ \\
\hline LIFT & $\begin{array}{l}\text { Make the learner be aware of learning skill } \\
\text { acquisition }\end{array}$ & $\begin{array}{l}\text { - (d2) Invisibility } \\
\text {-(d5) Simultaneous processing with rehearsal } \\
\text { - (d10) Acquisition of learning operator } \\
\text { - (d11) Acquisition of criteria for learning }\end{array}$ & $\begin{array}{l}\text { Visualization } \\
\text { Environment } \\
\text { Guidance Function }\end{array}$ \\
\hline REIFICATION & $\begin{array}{l}\text { Give appropriate language for his/her self- } \\
\text { conversation to acquire learning skills }\end{array}$ & - (d1) Segmentation of process & $\begin{array}{l}\text { Providing Domain } \\
\text { Specific Terms of } \\
\text { Learning Activities }\end{array}$ \\
\hline TRANSLATE & $\begin{array}{l}\text { Transfer the learning skill acquisition task } \\
\text { (LSAT) to a problem-solving task that } \\
\text { includes same task structure of LSAT. }\end{array}$ & $\begin{array}{l}\text { - (d7) A two-layer WM } \\
\text { - (d8) Multiple Processing }\end{array}$ & $\begin{array}{l}\text { Task Design (giving a } \\
\text { presentation task to } \\
\text { explain to other } \\
\text { learners) }\end{array}$ \\
\hline OBJECTIVIZATION & $\begin{array}{l}\text { Objectify her/his self-conversation processes } \\
\text { by externalizing them for learning } \\
\text { communications with other learners }\end{array}$ & - (triggering cognitive conflicts) & CSCL Environment \\
\hline
\end{tabular}

operation, (d5) simultaneous processing with rehearsal and (d7) a two-layer WM exist. In contrast, in performing on-going monitoring (i), that observes one's own learning processes, the difficulties of (d1) segmentation of process, (d2) invisibility, (d3) simultaneous processing with other cognitive activities, (d5) simultaneous processing with rehearsal, (d6) management of resource, (d7) a two-layer WM, and (d8) multiple processing exist.

Moreover, regarding (j) and (k), they represent factors of difficulty in performing learning skill acquisition processes: the difficulties of (d10) acquisition of learning operators and (d11) acquisition of criteria for learning processes exist, in addition to the factors of difficulties in performing meta-cognitive activities in problemsolving processes, i.e., (d3) simultaneous processing with their activities, (d5) simultaneous processing with rehearsal, (d6) management of resources, (d8) multiple processing, and (d9) planning.

\section{Design Model for Meta-Learning Support Scheme}

The meta-learning process model clarifies factors of difficulty in performing learning activities, whereas the conceptualizations described below clarify design concepts from the viewpoint of building a learning scheme to eliminate them.

Table 2 shows five concepts supporting meta-learning. They play a guiding role in the design of metalearning support systems. We conceptualize them from the engineering viewpoint of system development as a basis of functional design for facilitating meta-cognitive learning.

SHIFT means to stagger the time of developing learning skills after performing learning processes. By introducing two types of reflection, we explain SHIFT in detail.

- On-going monitoring means controlling cognitive processes IN problem-solving.

- Reflective monitoring means modifying cognitive processes AFTER solving the problem.

The SHIFT strategy enhances reflective monitoring by staggering the time of performing the meta-cognitive activities after doing problem-solving or learning.

Learning skill acquisition task is not always consciously performed by ordinary learners; it is necessary to provide appropriate stimulation which changes an "internal" self-conversation task to a usual conversation task to encourage their meta-cognition. We conceptualize LIFT as making the learners aware of learning skill acquisition: it plays a role of lifting a latent task under the boundary of consciousness in each learner's mind up to the boundary. 
REIFICATION gives appropriate language for the subject of meta-cognition: we cannot realize LIFT if we do not give appropriate REIFICATION.

Through OBJECTIVIZATION, we make internal self-conversation processes objective by discussing them with others. It contributes to cognitive conflicts $^{(2)}$ in a learner's mind, which facilitates the learner's metacognitive activities, triggered by the objective reaction of learning partners to the explanations.

TRANSLATE changes the learning skill acquisition task to a problem-solving task that includes the task structure of the learning skill acquisition task.

Based on these design concepts, developers can design valid meta-learning support schemes.

\section{Clarifying Design Rationale of a Presentation-Based Meta-Learning Support System}

The meta-learning process model and conceptualizations are integrated to design our meta-learning scheme and concrete support functions embedded into the system.

Table 2 presents correspondence among support functions based on the conceptualizations and their targets to eliminate factors of difficulty in performing meta-learning processes. Because of the space limitation, here, we describe the design rationale of our presentation-based meta-learning support system according to the model to show the usefulness of our framework. The literature ${ }^{(6)}$ should be consulted to comprehend concrete functions in detail.

According to SHIFT and TRANSLATE, we design presentation tasks where the learner must make presentation materials based on pre-learned knowledge. This task setting is important for the learner to examine meta-cognitive learning: if the learner must perform both learning and making presentations, the learner cannot allocate sufficient cognitive capacity to perform the meta-cognitive activities. This task setting corresponds to SHIFT.

SHIFT removes factors of (d3) simultaneous processing with other activities and eliminates (d6) management of resource, although it increases (d5) factors of inference of cognitive operation: it does not require on-going monitoring but prompts reflective-monitoring. Furthermore, TRANSLATE reduces factors of the twolayer WM and of multiple processing by translating learning process planning and learning skill acquisition tasks into the problem-solving (presentation) task.

In this environment, educational activities are shown in making presentation materials: "make the learner consider what functions might be extended," and so forth. This is designed based on REIFICATION and it decreases the difficulty of segmentation of the process.

In our system, the learner gradually details teaching plans by referring to such teaching activities, and finally gives concrete shape to all presentation materials and makes connections among the lowest educational activities and presentation materials. This is designed based on the LIFT design principle. It is intended to reduce the difficulty of invisibility and simultaneous processing with rehearsal.

LIFT is also realized as a function that provides the learner with guidance information for checking the validity of designed learning processes. Guidance information facilitating a learner's reflection on personal learning processes is shown at the time of moving to the following collaborative learning phase if educational activities that the teacher requires are not embedded into the learner's teaching plan. This is designed based on LIFT and it is intended to reduce the difficulty of acquisition of learning operators and acquisition of criteria for learning processes.

Then, the system provides each learner with respective viewpoints for discussion among learners. This function is also designed based on LIFT and is intended to reduce the difficulty of acquisition of learning operators and acquisition of criteria for learning processes.

OBJECTIVIZATION is realized as a computer supported collaborative learning environment. It is intended to trigger cognitive conflicts in the learner's mind through communication with learning partners' reactions, and to reduce the factors of difficulty of acquisition of learning operators and criteria for learning.

\section{Related Work}

By introducing the framework, we also can characterize other learning schemes from the viewpoint of learning scheme design according to design concepts. We, here, take a problem-posing learning scheme as an example.

In a problem-posing learning scheme ${ }^{(7,8)}$, learning skill acquisition tasks are translated to a problem-posing 
task: that includes SHIFT and TRANSLATE principles. In performing a problem-posing task, which includes the LIFT principle, a learner must be reminded of his own problem-solving processes. Furthermore, secondary effects occur because the posed problem must be solved by other learners, which includes the OBJECTIVIZATION principle. It does not include a REIFICATION principle. In this learning scheme, learners might be unable to follow this task translation because the problem-posing task requires heavier cognitive loads than problem-solving tasks do. Our learning scheme makes it easier to monitor and control learner's learning activities by translating learning skill acquisition task into the problem-solving task based on the TRANSLATE principle.

\section{Concluding Remarks}

We presented our model-oriented approach and proposed a meta-learning process model by extending Kayashima's computational model for characterizing meta-learning activities. Then, we presented our conceptualizations as a basis of learning scheme design. Furthermore, a meta-learning process model and the conceptualizations were integrated to support design of meta-learning systems based on a deep understanding of meta-learning processes. The conceptualizations play a guiding role in the design of meta-learning support systems. Moreover, the meta-learning process model plays an important role in accumulating and sharing experiences of individual learning system development, because the design rationale of each support function embedded in our meta-learning support system can be understood based on the model.

\section{References}

(1) Ikeda, M. and Hayashi, Y.: “Ontology Based Modeling of
Learning Activity", Transactions of Japanese Society for Information and Systems in Education, Vol. 21, No.3, pp. 168-177 (2004) (in Japanese).

(2) Hirashima, T. and Horiguchi, K.: "Error-Visualization for Learning from Mistakes", Transactions of Japanese Society for Information and Systems in Education, Vol. 21, No.3, pp. 178-185 (2004) (in Japanese).

(3) Hayashi, Y., Bourdeau J. and Mizoguchi, R.: "Strategycentered Modeling for Better Understanding of Learning/Instructional Theories", International Journal of Knowledge and Web Intelligence, Vol. 1, No. 3/4, pp. 187-208 (2010)

(4) Kayashima, M., Inaba A. and Mizoguchi, R.: "What Do You Mean by to Help Learning of Metacognition?", Proc. of 12th Artificial Intelligence in Education (AIED2005), Amsterdam, July 18-22, pp. 346-353 (2005).

(5) Kayashima, M., Inaba A. and Mizoguchi, R.: "A Framework of Difficulty in Metacognitive Activity", Transactions of Japanese Society for Information and Systems in Education, Vol. 25, No. 1, pp. 19-31 (2008) (in Japanese).

(6) Seta, K., Noguchi, D. and Ikeda, M.: "Presentation-Based Collaborative Learning Support System to Facilitate Meta-Cognitively Aware Learning Communication", The Journal of Information and Systems in Education, Vol. 9, No.1, pp. 3-14 (2011).

(7) Nakano, A., Hirashima, T. and Takeuchi, A.: "Developing and evaluation of a computer-based problem posing in the case of arithmetical word problems", Fourth International Conference on Computer Applications, ICCA2006, Yangon, Myanmar, Feb. 23-24 (2006).

(8) Kojima, K. and Miwa, K.: "A Case Retrieval System for Mathematical Learning from Analogical Instances", Proc. of the International Conference on Computers in Education (ICCE), Hong Kong, Dec. 2-5, pp. 1124-1128 (2003). 


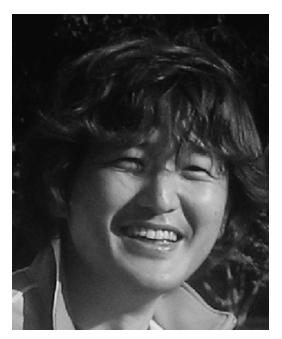

Kazuhisa Seta received the Ph.D. from Osaka University in 1998. He is currently an associate professor in the Graduate School of Science, Osaka Prefecture University. His research interests include software engineering, intelligent tutoring systems, human resource management and ontological engineering. He is a member of JSAI, IEICE, IPSJ and JSiSE.

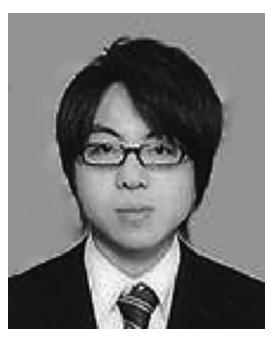

Hiroshi Maeno received the M.S. from Osaka Prefecture University in 2010. He is currently with Simplex Technology Inc. His research interests include intelligent tutoring systems.

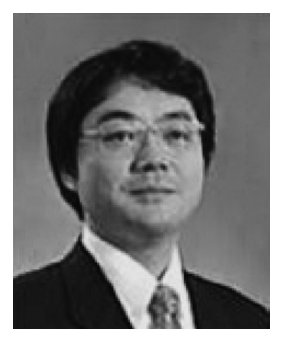

Mitsuru Ikeda received the B.E and M.E. from Utsunomiya University in 1984 and 1986, respectively. He received the D.E. from Osaka University in 1989. He is currently a professor in Japan Advanced Institute of Science and Technology. His research interests include ontological engineering research in the field of e-learning, knowledge management, semantic web. He has received the Best Paper Award of Japanese Society for Artificial Intelligence and the Outstanding Paper Award of the International Conference on Computers in Education in 1996 and 1999, respectively. Currently, he heads the Japanese committee of ISO/IECJTC 1/SC36/WG2 (Learning technology for collaborative learning). 